\title{
La fiesta de La Tirana en la literatura obrera ${ }^{1}$
}

\author{
Bernardo Guerrero Jiménez ${ }^{*}$ ) \\ RESUMEN
}

En este artículo se discuten las relaciones entre la llamada literatura obrera y la fiesta de La Tirana en el Norte Grande de Chile. Se estudia el modo en cómo la novela, en este caso, Los pampinos de Luis González Zenteno y La luz viene del mar, de Nicomedes Guzmán, representan a esta actividad masiva, religiosa y popular. Ambos autores más allá de sus estilos literarios y generacionales, se inscriben dentro de una episteme moderna e ilustrada que los hace concebir a esa fiesta como algo del pasado, pagano, supersticioso y a superar por la fuerza de la historia. Elegimos estas dos ya que son las únicas que se refieren a esta manifestación religiosa.

\section{Palabras clave:}

\section{Literatura obrera - La Tirana - religión popular.}

\begin{abstract}
This article discusses the relationships between the so-called "working class" literature and the carnival of La Tirana in the North of Chile. It is studied how in the novels Los Pampinos by Luis González Zenteno and La Luz viene del mar by Nicomedes Guzmán, represent this religious and popular activity. Both authors, besides the different literary styles and generational affiliation, are inscribed in a modern and "enlightened" set of conceptions that understand this feast as something from the past, pagan and superstitious and that will be overcome by the force of History.
\end{abstract}

Keywords:

Working class literature - La Tirana - popular religion.

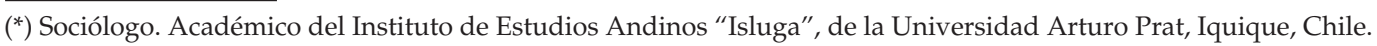

Artículo recibido el 21 de enero de 2011. Aceptado por el Comité Editorial el 14 de mayo de 2012.

Correo electrónico: Bernardo.Guerrero@unap.cl

${ }^{1}$ Trabajo escrito bajo el Proyecto Fondecyt № 1100807, “Bailes Religiosos, Iglesia Católica y Estado: La fiesta de La Tirana en el Bicentenario". 


\section{Salitre y religión}

La explotación del salitre en el Norte Grande de Chile, produjo no sólo un fenómeno económico, político y social, sino que también cultural. La prensa y el teatro obrero son los hechos más destacados de este último aspecto (Bravo, 1986). Todo ello sin contar con la aparición de otros hechos como los deportes modernos que aglutinaron a buena parte de los obreros y ayudaron a canalizar el ocio, y de paso producir identidad nacional en un territorio recientemente anexado a la soberanía nacional (Guerrero, 2008).

Dentro de los fenómenos culturales, la realización de la fiesta de La Tirana, es quizás la más sobresaliente. Aunque sus orígenes son más antiguos, alcanza con la era del salitre su mayor apogeo (Núñez, 199). Esta fiesta se realiza cada 16 de julio en el pueblo del mismo nombre, en el Norte Grande de Chile; tiene un fuerte impacto sobre la vida cotidiana de hombres y mujeres que habitan esa extensa geografía. No solo de Chile, sino que de Perú y Bolivia se desplazan los peregrinos y las peregrinas para venerar a la "China" como cariñosamente se le dice.

Para los miles de hombres y de mujeres que van cada 16 de julio a la fiesta de La Tirana, el año se divide en dos: antes y después de la fiesta. Esta forma de estructurar la vida cotidiana implica que la rutina diaria se acomoda a esa fecha. Ir a la fiesta de La Tirana se convierte en lo más importante. Ese día, el pequeño pueblo de La Tirana congrega a más de cien mil personas.

Hombres y mujeres se desplazan en busca de salud y bienestar. Esos son los motivos fundamentales de sus mandas. En Iquique, la ciudad costera más próxima al santuario, ubicada a $60 \mathrm{~km}$, los peregrinos durante todo el año desarrollan diversas actividades orientadas a presentarse del modo más óptimo a la fiesta. Una de ellas son los ensayos y la búsqueda de recursos para alojarse de mejor forma, en los cerca de diez días que permanecen en ese pueblo. La fiesta de La Tirana estructura buena parte de la sociabilidad de la cultura religiosa y popular del Norte Grande de Chile.

\section{La fiesta de La Tirana y las ciencias sociales}

El fenómeno de la fiesta de La Tirana, no ha sido un tema de atención para las ciencias sociales, pese a su existencia por más de un siglo, y a la alta convocatoria que provoca. En el año 2011, llegaron cerca de 200 mil peregrinos. Ha llamado la atención de folcloristas, en primer lugar, que se han centrado en los aspectos estéticos de esta manifestación como el baile, la danza y los trajes.

Las ciencias sociales, y sobre todo la antropología social y cultural, desde hace un par de décadas, han empezado a prestar atención a esta masiva actividad religiosa popular. Ha sido van Kessel, el que más ha estudiado los santuarios del Norte Grande de Chile: Ayquina, Las Peñas y La Tirana. En otro trabajo hemos prestado atención a la obra de este holandés (Guerrero, 2004). 
El porqué de esta tardanza hay que ubicarla en la matriz ilustrada que dominó a las ciencias sociales a lo largo del siglo anterior. La sociología latinoamericana, tanto en su vertiente dependentista como desarrollista, anunciaron el fin de la religión. La promesa de la secularización, como ya ha sido indicado en muchos trabajos (Hervieu-Léger, 2004) no se cumplió. La vitalidad de los santuarios del Norte Grande así lo demuestra. Cada año aumentan los bailes religiosos. La Iglesia católica ha debido frenar la membresía de éstos. El libro de van Kessel, Lucero del Desierto (1980), significó un punto de quiebre en la tradición sobre los estudios del peregrinaje. El autor opta por una visión desde dentro, tratando de entender la lógica de este movimiento, y por otro lado, por la vía de la antropología simbólica, en especial por el aparataje teórico de Turner, dan cuenta de la complejidad y riqueza de una conducta que se niega a ser etiquetada como folclórica o tradicional. A partir de los años 60, empiezan en las universidades, a producirse algunas tesis de grado, en este tema. En la actualidad el panorama es más alentador. Las ciencias sociales, sacudidas de la matriz positiva e ilustrada, se han abierto a estudiar estas manifestaciones religiosas. Por otro lado, la producción de documentales con base antropológica ha ido en aumento. La producción de Omar Villegas, Francisco Gedda, Rafael Durán y del equipo de la Universidad Arturo Prat, por sólo nombrar a algunos, indican una preocupación más allá de lo folclórico.

La fiesta de La Tirana fue objeto de tratamiento periodístico. En algunas publicaciones como la revista "En Viaje", se da cuenta de esta y otras manifestaciones religiosas. El foco de atención seguía siendo, sin embargo, los aspectos folclóricos. En la prensa local, sobre todo en "El Tarapacá", la cobertura es mínima y sólo se limita a informar sobre el desarrollo de la misma. Sólo a partir de los años 80, cuando la Iglesia católica controla todos los aspectos de la fiesta, la cobertura se amplía, hasta el punto que los bailes aparecen hasta en la vida social, posando para el fotógrafo.

En el llamado relato de la pampa salitrera (Moretic, 1962), las referencias a los santuarios del Norte Grande de Chile, son casi inexistentes. Las dos novelas que analizamos parecen ser la excepción. La majestuosa novela de Sabella, Norte Grande (1944), al decir de Moretic: "pareció estar destinada a llenar el notorio vacío que en la novelística chilena significaba la inexistencia de una novela que reflejara la apasionante realidad del mundo salitrero" $(1944$, p.46). Lo que sucedió es que para el antofagastino, la realidad del mundo salitrero, no incluía la dimensión religiosa. Un solo capítulo, breve por lo demás, el personaje, según el autor, "No era ni creyente ni ateo" $\left(1997\right.$, p. 186) ${ }^{2}$. Además se refiere a la religión oficial, en este caso, el catolicismo. El catecismo, continúa Sabella, le llamaba la atención. 3785, así se identifica el personaje, se entretiene leyendo el catecismo, pero pronto empezará a leer "El manifiesto Comunista", se produce la conversión al comunismo, lo que no le impide reconocer que dos de los doce mandamientos siguen siendo importante. No robar y no desear los bienes ajenos. Este cruce entre catolicismo y comunismo, ya se deja en evidencia en la novela fundacional Tarapacá de Osvaldo López y Nicanor Polo. Moretic, al parecer no conoció esta novela ${ }^{3}$.

\footnotetext{
${ }^{2}$ Citamos la edición del año 1997, de Lom, Santiago, Chile.

${ }^{3}$ Fue reeditada por la Fundación Crear, en Iquique, el año 2006.
} 
La matriz ilustrada, una vez más, impedía ver lo que era evidente. Siguiendo a Moretic, cuando analiza la obra de Mario Bahamonde, se detiene en el cuento "El milagro del viejo Avelino" incluido en el libro Pampa Volcada (1945), dice: "Relata la forma irreverente de que se vale un obrero para burlarse de la supertición de los pampinos" (1962, p. 51). Se trata de una animita, y de su culto, en una oficina salitrera. Hay que hacer notar que tanto, el analista como los creadores, en este caso Moretic y Bahamonde, están aprisionados en el paradigma marxista de la época. El culto a las animitas, algo tan frecuente en el Norte Grande desde fines del siglo XIX (Guerrero, 2011), es visto como una superstición. La trágica muerte de un pampino, atropellado por una locomotora, produce la construcción de un pequeño templo. Las mujeres son las principales devotas: "Acrecentada en esta forma la autoridad que la mujer ejercía en el dominio de lo sobrenatural, su respuesta fue enérgica" (1945, p. 83). Dos trabajadores, incrédulos (¿alter ego del autor?) destruyen la animita. La oficina salitrera se moviliza y van a dejar los restos al cementerio. Bahamonde cierra el relato de este modo: "La tradición es un río grande, en cuyo caudal caben holgadamente los milagros y las diabluras. La fantasía empuja el torrente con un ronroneo parloteador" (1945, p. 85).

\section{La representación literaria de la fiesta de La Tirana}

La representación literaria de la religiosidad popular en el Norte Grande, como ya se ha dicho, no es abundante. Y cuando intenta representarla, lo hace desde la matriz ilustrada. Tal vez las únicas excepciones la constituyen la novela de Hernán Rivera Himno de un ángel parado en una pata, y el relato etnográfico, Pescadores y Peregrinos de Tocopilla de Juan van Kessel. Ambas obras analizadas en "Están reventando las rosas..." (Guerrero, 2002, pp. 80-100).

Nos proponemos en este trabajo indagar acerca de la forma que tiene la llamada literatura obrera ${ }^{4}$ del Norte Grande de representar esa actividad que mantiene su vigencia desde fines del siglo XIX. La idea central, a modo de hipótesis, es que la fiesta de La Tirana, ocupa un lugar más bien marginal en el discurso literario obrero. Y más aún, las escasas referencias que de ella se tienen se basan en estereotipos y lugares comunes de la época. Esto tiene que ver con las visiones acerca de la religión que dominan en la época. Sobre eso y otros aspectos ya volveremos. Marginalidad y desprecio por los ejes sobre los cuales se levantan estos textos.

Citamos el origen de la fiesta, estructurada en la siguiente leyenda:

Nusta Huillac, hija del último Gran Sacerdote de los Incas, alimentaba un odio mortal hacia los conquistadores españoles. Cuando Diego de Almagro volvió al Perú, ella se retiró acompañada de sus fieles guerreros a la Pampa del Tamarugal, en aquel tiempo rica región de bosques, donde persiguió y mató a centenares de españoles. Recibió el sobrenombre de Tirana, de allí el de la localidad de La Tirana. Un día sus soldados hicieron prisionero a un portugués y lo llevaron a su presencia. Se trataba de Vasco de Almeyda que venía de Huantajaya donde explotaba una mina de oro (?). La Ñusta

\footnotetext{
${ }^{4}$ Las formas de adjetivarlas son diferentes: literatura del salitre, literatura obrera, literatura regional, narrativa regional, relato salitrero. Usamos todas esas en este trabajo, en este caso novela obrera, novela regional, novela salitrera.
} 
se enamoró de él, pero esto fue su ruina. Por amor se convirtió a la religión de los conquistadores. La pareja fue sorprendida por los guerreros indios cuando se disponían a huir. La princesa y su amante fueron muertos en el campo.

Cien años después un monje, Antonio, encontró en ese mismo sitio una virgen tallada en la roca y una cruz de madera e hizo construir una capilla, actualmente centro del culto de los miles de peregrinos (Van Kessel, 1987, p. 11).

Lo dice la leyenda ya citada: Una princesa india, cruel y despiadada, toma prisionero a un portugués que había trabajado en Huantajaya. Se enamora y se convierte al cristianismo. Ambos son ajusticiados. Tiempo después un fraile encuentra un montículo y sobre él, una cruz. Esta es la versión que el historiador Cuneo Vidal cuenta. Así nace la peregrinación a la "China".

\section{La Tirana en la novela obrera}

La referencias a la ficción literaria en los tiempos de la industria del salitre, ha sido bien estudiado por Yerko Moretic (1962), Mario Bahamonde (1966), José Antonio González (1983), Mauricio Ostria (2005), Osvaldo Maya (1998) Pedro Bravo Elizondo y Bernardo Guerrero (2000), (2002), entre otros. Todos ellos han enfatizado el nacimiento de una narrativa que busca representar las duras condiciones de vida a la que estaban expuestos hombres y mujeres, y sobre todo, a enarbolar un proyecto de clase que condujeran a la revolución socialista y con ello a poner fin a la explotación del hombre por el hombre. Tal era el espíritu de la época.

La literatura obrera del Norte Grande surge por mediación de la industria salitrera. Los temas recurrentes de esta actividad son la denuncia y la protesta, y ello en un tono y una voz de un obrero ilustrado y emancipado, por lo tanto, ateo. Se trata de un corpus que se inspira en las líneas dominantes de las ideas de la Ilustración decimonónica del siglo XIX que se introduce en la zona, ya sea bajo la forma de la masonería o bien de grupos socialistas y anarquistas. En todos ellos, el común denominador es la idea del progreso, la razón como instrumento cognitivo fundamental y la posibilidad de alcanzar una sociedad mejor. Así por ejemplo, en la novela fundacional de la literatura obrera Tarapacá (1903/2006), escrita por Osvaldo López y Nicanor Polo, bajo el seudónimo de Juanito Zola, estos ejes son dominantes (Guerrero, Bravo-Elizondo). Juan Pérez, es el personaje, obrero e ilustrado, anarquista y masón que bien simboliza las ideas anteriores (Guerrero, 1996). Este modelo de personaje será el que inspirará la larga tradición de esta novela. En el caso de la novela ya citada, la religión es vista en una doble condición. Se le liga a la iglesia católica y por lo tanto se cuestiona su rol de alianza con las clases dominantes, y en términos religiosos se le vincula a un Cristo, humanizado y revolucionario ${ }^{5}$.

En el plano de las ideas la novela obrera se edifica sobre dos ejes: la conquista del socialismo y de una sociedad mejor, más justa y más solidaria. Y por otro lado, un profundo y sentido espíritu anti-religioso, aunque en rigor pareciera ser más correcto,

\footnotetext{
${ }^{5} \mathrm{Al}$ decir de Mario Bahamonde, el despertar de la literatura salitrera está en el poema de Clodomiro Castro, Las pampas salitreras, editado en Iquique el año 1896 (1966, p. 25).
} 
hablar de anticlericalismo. Tema dominante a comienzos del siglo XX, en el Norte Grande, el anticlericalismo se instaló en el imaginario de la época y conjugó alianzas bastante específicas: masones con dirigentes obreros de izquierda. Y por la otra vereda, conservadores y católicos.

Ostria realiza una periodización del desarrollo de la novela del salitre. Distingue tres períodos. 1. El relato naturalista, testimonial, biográfico, documental, con personajes planos, a menudo tipificaciones, con importantes referencias a la geografía inhóspita y a la cruda realidad social (1900 a 1930: la novela Tarapacá, por ejemplo; 2. El relato neorrealista en el que los conflictos sociales se presentan en una escritura artística, tanto por el cuidado de lenguaje, como por la disposición narrativa, preocupada por ordenamientos, clímax, gradaciones, caracterización de personajes, etc. (19401970), Norte Grande de Sabella, Los pampinos de González Zenteno; 3. El relato posmoderno, evocativo a veces elegíaco, paródico, humorístico en el que los aspectos de denuncia aparecen suavizados por la visión memoriosa y, veces, tierna de narrador y los hechos reales, convertidos a episodios donde prolifera la dimensión imaginaria. Esta tendencia es dominada por la escritura de Hernán Rivera Letelier (2005, p. 4).

\section{Poesía obrera y religión}

La lectura de la poesía obrera de la época, por ejemplo, deja bien en claro que las protestas de los trabajadores no son en contra de la existencia o no de Dios, sino de la actuación del clero a quien se identifica en alianza con la clase dominante o bien gozado de un estilo de vida ostentoso:

Que los bienes ajenos no sean codiciados

Nos enseña la iglesia, nos dice el sacerdote

Mas la iglesia y el clero, van más adelantados

Los bienes codiciando, acaparando dotes!

(Pérez, 1996, p. 35).

O esta expresión:

El cura no sabe arar

Ni sabe enyugar un buei

Pero por su propia lei

El cosecha sin sembrar

Cuando se afirma que la idea del anticlericalismo no significa necesariamente ateísmo, citamos este otro poema obrero de la época:

Por amor cantan las aves

Por amor las hizo Dios

Por amor vine yo al mundo

Por amor te quiero yo

Y aun cuando se cuestiona la religión, no se la cuestiona en sí, en su rasgo esencial, del tipo que es una conciencia falsa sino por el tipo que asume. Para los obreros, por 
ejemplo, los mandamientos de la verdadera religión son:

1. Amar á la humanidad sobre todas las cosas.

2. Mirar en cada ser humano un ser humano

3. Ser buen hijo. Excelente esposo, amante padre y mejor ciudadano.

4. Honrar á la ciencia y el trabajo, prestar ayudar al débil, al huérfano y al pobre sin amparo.

5. No herir con la lengua, ni matar con las manos.

6. No engañar á nadie, ni hurtar el trabajo ajeno

7. No codiciar lo del otro, ni vivir a costas de los demás.

8. Adorar a Dios en las obras de la naturaleza y no en personas de seres mitolójicos metafísicos o teolójicos.

9. Mejorar las condiciones morales, materiales de la mujer que es nuestra compañera.

10. No hacer a otros lo que no nos agrada ${ }^{6}$.

No hay que olvidar por cierto que los autores de estos poemas citados son obreros. En forma periódica publican en la prensa sus obras. No ocurre lo mismo con la llamada novela obrera que por lo general, está escrita por obreros ilustrados, es decir, por cuadros que han tenido una formación política, ya sea en el movimiento anarquista o en el socialista. Y que tienen acceso a la imprenta como medio de distribución de sus ideas. Para el caso que no ocupa en el presente trabajo, prestamos atención a la obra de dos autores. Luis González Zenteno (1909-1960) y Nicomedes Guzmán (1914-1964)7. Ambos autores pertenecientes a la generación del 38, hicieron del naturalismo su mejor arma para describir y denunciar las míseras condiciones de vida de los trabajadores chilenos, y en especial del norte chileno. Ambos tienen un origen proletario.

El primero escribió las novelas Caliche (1954), Los pampinos (1956) y la novela Piratas en el desierto (1953). Además de una serie de ensayos. Instalado en Santiago publicó Una lágrima para el juez, novela con aire urbano. Por su parte Guzmán, publicó una extensa obra entre la que se destaca Los hombres oscuros (1939), La Sangre y la Esperanza (1943). En el caso del Norte Grande editó el año 1951 la novela La luz viene del mar, ambientada en el barrio El Colorado y en la pampa salitrera.

Lo común de ambos y siguiendo el razonamiento de Mauricio Ostria, es que "narraron la pampa desde el horizonte ilustrado de las ciudades". Y este no es un dato menor ya que permite entender mejor el tratamiento de ciertos temas y el modo en que se abordan. La hipótesis que sustento se basa en la idea de que estos novelistas, al abrazar una matriz de pensamiento moderno, ilustrado y socialista, se adhieren a una forma de ver el mundo, en que la religión es vista de acuerdo a los predicamentos de la época como opio del pueblo, y en segundo lugar, en sostener que hay una relación de sinonimia entre clero y religión. La fiesta de La Tirana, es vista tal como lo ven los sectores modernos de la ciudad, sean de izquierda o de derecha: una actividad que

${ }^{6}$ Publicado en el Pueblo Obrero. Interdiario Pampino. Fundado el 18 de septiembre de 1906. N² 244. Iquique, sábado 27 de abril de 1907. Sin número de página.

${ }^{7}$ Hay quienes lo ubican dentro del realismo socialista (Alvarez, 2009, p. 16). 
retrotrae al pasado, y que condena a los sujetos que participan en ella, a vivir en la superstición y en la ignorancia. A ello se le suma la mirada de la Iglesia católica que conceptualiza a esta manifestación religiosa y popular como pagana y en el mejor de los casos, como folclórica.

En términos generales la festividad de La Tirana que se viene realizando, en forma masiva, desde fines del siglo XIX a la fecha, no se encuentra representada en la llamada novela obrera. Los casos que vamos a citar, son excepciones, de parte de una literatura, que porta un mensaje de clase e ideológico que ve a la religión como un resabio del pasado que hay que superar.

Como bien se sabe esta festividad tiene una clara connotación popular. Cada 16 de julio miles de hombres y mujeres, acuden al pueblo del mismo nombre a venerar a la Virgen del Carmen. Con la explotación del salitre y la consabida llegada de gentes de todas las latitudes esta fiesta alcanzó una dimensión masiva y popular.

De clara herencia andina (Van Kessel, 1986) se fue combinando con la invención del proletariado que año a año, le ha ido integrando elementos de la sociedad ambiente. Se puede decir que los mismos obreros que se inmolaron en la escuela Santa María, el 21 de diciembre de 1907, le bailaban a la Virgen.

Pese a los augurios de la modernidad de los años 70, que anunciaba el fin de la religión, esta manifestación ha ido cada año creciendo, desafiando con ello esos sombríos pronósticos. Los grupos de bailes poseen una sólida organización que sin duda alguna, la tomaron de las estructuras obreras de los tiempos del salitre, toda vez que han sabido asimilar creativamente los insumos que la modernidad tecnológica les ha brindado. Por ejemplo, gracias a la Zona Franca de Iquique (ZOFRI) han ido mejorando sus bandas de músicos, sus trajes, y por cierto la movilización gracias a lo barato que resulta comprarse un vehículo. Por decirlo de un modo, la tecnología le ha servido para mostrarse a una sociedad que en muchos de los casos les ha sido adversa. Muchos de los bailes religiosos poseen páginas web, blogs, etc. Pero, en lo medular, siguen profesando una fuerte religiosidad popular cuyo eje central es la Virgen del Carmen.

\section{La Tirana y la novela obrera}

Luis González Zenteno en su novela Los pampinos, recrea la matanza de La Coruña ocurrida en el año 1925 en la oficina del mismo nombre. Su personaje central Carlos Garrido al igual que los miles de pampinos, viene del sur. En este caso de Aconcagua. Se impacta por el desierto y por la ciudad cosmopolita ${ }^{8}$ que era en ese entonces Iquique.

\footnotetext{
${ }^{8}$ Mario Bahamonde, Andrés Sabella y Luis González Zenteno, entre otros, hablan del carácter cosmopolita del Norte Grande. Por ejemplo: "Los hombres llegaron a estos lugares atraídos por una llamarada fascinante: la plata de Chañarcillo, la plata de Caracoles, la plata de Huantajaya, el cobre de Chuquicamata, el esplendor del salitre y sus posibilidades de vida fácil, el auge de los puertos, el cosmopolitismo de sus bahías. Avalanchas humanas acudieron a estas tierras. Y la otra impresión que produce la zona es la aventura. Todos llegaron aquí movidos por el incentivo aventurero; el negocio fácil, el trabajo rendidor, el contrabando, el golpe de suerte, etc. Sin embargo, mirado el problema del poblamiento nortino con más calma, resulta distinto. Se trata de un lento proceso de integración; integración del hombre a esta tierra y, además, integración de la tierra a la economía nacional (Bahamonde, 1978, p. 13)". En rigor, esta expresión es más bien un deseo que una realidad. Es mejor hablar de multiculturalidad. Cosmopolita alude a un deseo de la modernidad de construir un hombre de un solo mundo. O sea europeo (Ver Chernilo, 2010).
} 
La llamada literatura nortina, en la autoría de Luis González Zenteno, es quizás el único que retrata a los indígenas que habitan en el Norte Grande y que en la época del salitre, jugaron un rol de arrieros y de comerciantes. Sin mencionar la palabra Pachama dice:

Los indios sentían por la pampa un respeto religioso. Pampa y cordillera eran para ellos expresiones telúricas de una misma divinidad. Allá las dentadas moles, aquí sus llanuras, allá sus dioses monolíticos y temibles, acá sus dilatadas sabanas de arena, protegiendo y aislando los pies de los volcanes, de los extraños y maldadosos hombres de las llanuras costeñas (González, 1954, p. 49).

Y los describe:

Hombres morenos, chicos, encorvados, buscaron refugio en sus faldeos y rayaron sobre las lisas superficies de las piedras, curiosos signos ${ }^{9}$. El Tata Jachura, sereno, grave, blanca de nieve su cabeza milenaria, exhibía en su tórax poderoso, en su plexo nervudo, en sus bíceps modelados por el fuego de los cataclismos, admoniciones y consejas (González, 1954, p. 49).

Luis González Zenteno, recrea un diálogo entre un cura y Elías Lafferte en Iquique. Ambos, se sienten miembros de una misma causa, pero con diferentes dioses. La figura del apóstol y del revolucionario aparece como cara de una misma moneda.

Discutieron hasta que el reloj de la Plaza Prat difundió las lentas y graves campanadas de la medianoche, y se comprometieron a reanudar la controversia en una próxima oportunidad, pues como ocurre siempre en estos casos, ninguno se sentía derrotado.

¡¡Es admirable este fraile! -comentaba Lafferte, mientras avanzaba por Vivar en dirección a la Foch, rodeado de compañeros-. ¡Con sus condiciones de apóstol podría haber sido un revolucionario de lujo!

Y por su parte, el Vicario, pensando en don Elías, se lamentaba.

¡Qué gran pastor de almas ha perdido nuestra religión!“ (González, 1954, p. 158).

Lo anterior para dar cuenta de los tópicos en que se mueve la literatura obrera respecto al tema de la religión.

El autor de Los Pampinos, construye este relato que a continuación cito en la que sitúa dos hechos puntuales cuyo protagonista es el pueblo, pero con énfasis diferentes:

Dos espectáculos atrajeron por esos días la curiosidad pública: la apertura del Rancho de los Cesantes, ubicado en Serrano esquina de Aníbal Pinto, en unas viejas bodegas desocupadas de Duncan Fox y Cía., y la preparación de las fiestas religiosas de La Tirana, que volcaba en las calles tropeles de devotos chunchos (González, 1956, p.123).

\footnotetext{
${ }^{9}$ Se refiere a geoglifos y petroglifos que abundan en el Norte Grande de Chile.
} 
Por un lado, el uso de ciertos términos como espectáculo, tropeles y devotos chunchos, llaman la atención.

La noción de espectáculo refiere a suceso o escena que atrae la atención y que produce asombro, placer, pena, indignación, etcétera, en quien lo presencia. Se trata de eventos en que se establece una distinción entre un yo que observa y otro que desarrolla determinadas acciones. De ese modo la fiesta de La Tirana es vista como algo externo. La noción de tropeles, por su parte, indica la existencia de una masa desordenada y ruidosa. Algo que no tiene nada que ver con el orden que los bailes religiosos muestran en su organización y disciplina. Por último, la expresión chunchos, palabra de origen aymara, que se usa, por parte de la elite ilustrada para englobar al conjunto de devotos que año a año acuden a la fiesta de La Tirana, sirve sólo para caracterizar una generalidad. La palabra chuncho, en su globalidad, no deja ver la especificidad de otros grupos y además vincula casi de un modo directo a estos grupos a la población india, que además es vista como reducto de la tradicionalidad. Con el correr de los años, esta palabra ha sido reemplazada por el de bailes religiosos.

Lo que hace coincidir a la literatura obrera con la Iglesia católica es sin duda, la descalificación de la actividad de los peregrinos. En el caso de la novela obrera es evidente:

El pasado volvía a ocupar su lugar con toda la fuerza de su tradición. Resucitaba la fe supersticiosa del hombre primitivo que creía en brujos y maleficios y se ponía cubierto de los mágicos poderes con plumas, collares, máscaras, pieles, guairuros, piedra imán y otras fruslerías (González, 1956, p.123).

La matriz ilustrada que engloba al pensamiento de la época es evidente. El pasado es visto como algo a superar. No hay que olvidar que el otro componente esencial de este tipo de pensamiento es el peso que se le otorga a la idea del progreso: hay que superar el pasado y conquistar el futuro. La fiesta de La Tirana es para este tipo de pensamiento una puesta en escena de la tradición y de la superstición. El relato termina con una caricatura de los adornos que hombres y mujeres ponen en sus trajes.

\section{La luz viene del mar}

Casi una década después, el escritor chileno Nicomedes Guzmán escribe la novela ya citada. Le dedica un par de párrafos a la fiesta de La Tirana. Al igual que González Zenteno, su pluma ilustrada y moderna, incapaz de comprender el fenómeno, dice: "Eran extrañas y bellas las fiestas de La Tirana" (1963, p.167).

Sin embargo, nos da información bastante detallada acerca de cómo eran las fiestas, el ambiente y el pueblo que recibe a los peregrinos:

El puerto se movilizaba entero casi en su población y en carros subían hombres, mujeres, niños y perros a la pampa.

El derruido pueblo se encontraba en plena Pampa del Tamarugal, enclavado en medio de la angustia arenosa, al oriente de Pozo Almonte. Se llegaba a él por huellas donde los vehículos se hundían hasta los ejes" (Guzmán, 1963, p.167). 
Es por cierto una mirada desde afuera, realizada por un escritor ilustrado, que bajo el mandato de la razón, está impedido por ver la lógica que anima estas conductas. Escribe:

Allí estaban los "diablos" grotescos y chillones, haciéndoles cancha a los bailarines. Allá estaban devotos y devotas, arrastrándose desde el calvario, elevado en las afueras del pueblo, hasta la iglesia, de rodillas, sangrantes las piernas, quejumbrosos, fatigados, vivas las lágrimas demarcando su tránsito en los rostros compungidos, tragediosos (Guzmán, 1963, p. 168).

Donde algunos ven belleza el autor ve conductas grotescas. La narración de ese acto tan personal como dramático que es la manda, un rito que implica asumir en términos del dolor la condición de pecador, es realizado sin prestar atención a consideraciones psicológicas y de la fe. Esta narrativa impresionista hace que el autor sólo se quede con lo manifiesto; con lo que su matriz le permite aprehender.

Relata luego cómo era el templo y el altar:

Y allá estaba la Virgen, La Tirana, en un altar de una de las capillas laterales de la amplia iglesia de tres torres, engalanada de sedas, monedas y billetes, exhibiendo sobre el cuerpo de piedra las riquezas que el culto y la fe de tarapaqueños de todos los cantones, bolivianos, peruanos, bolivianos e indígenas, le brindaban en el día del Carmelo. El niño, también, y la efigie del pastor que la descubriera, lucían sus ofrendas valiosas (Guzmán, 1963, p. 168).

El relato que hace de la fiesta es minucioso:

En los costados lucíanse las riquezas y las joyas de la santa (sic), sederías auténticas de la China, estandartes. Allí estaba el maravilloso manto encarnado, bordado de oro y plata, que mandara a confeccionar al Oriente un ganadero de Tocopilla. Fastuosidad, espesura de almas en recogimiento, velas ornamentadas que se desangraban en sebo y rancios olores, como si en ellas se desangrará el propio tiempo (Guzmán, 1963, p. 168).

Nótese aquí cómo la fantasía del autor, algo permitido en la novela (sin ficción no hay novela), le permite hablar de santa en vez de Virgen, sedas de la China, fastuosidad. Y agrega:

Era una fiesta pagana que el culto había convertido en religiosa. El pueblo de La Tirana, habitado por unas tres o cuatro familias de leñeros, con sus burros llagosos y rebuznantes, se atiborraba de romeros. Las casas semiderruidas eran alquiladas por metros y se llenaban de devotos que tendían allí sus jergones y cobijas. En las inmediaciones, cerca del hundido cementerio, se elevaban carpas, y los menos amparábanse bajo la umbría incipiente de los tamarugos y algarrobos (Guzmán, 1963, p.169).

Importa destacar aquí la información que entrega de la fiesta. En todo caso y como ya lo habíamos advertido, esta fiesta nunca llamó la atención de la novela obrera. Por lo mismo que estaba asociada a la superstición y al paganismo. En otras palabras, estos bailarines no tenían conciencia de clase. Lo que no se sabía es que muchos de 
éstos eran también dirigentes de los obreros. Al decir que era una fiesta pagana, está afirmando la clásica distinción del espíritu ilustrado, es decir, la antinomia entre civilización y barbarie.

\section{A modo de conclusiones}

La discursividad presente en las dos novelas analizadas deja ver como ya ha sido señalado, el fuerte acento caricaturesco que ambos autores les imprimen a la fiesta de La Tirana. Y es plausible que así haya sido. La matriz epistémica en la que los dos autores se inscriben, no le permite ver más allá de lo que el paradigma dominante de la época les exige. El modelo de este tipo de narración parece encontrarse en la novela editada en 1903 en Iquique, Tarapacá.

Modernos de izquierda tanto González como Guzmán, construyen una novela de clase que percibe a los obreros que se agrupan en los bailes religiosos como prisioneros de la tradición y de la superstición. Sólo la razón y la acción partidaria y proletaria corregirán estas desviaciones. El ideal de la Ilustración llevado a su máxima expresión.

Pero hay que distinguir un par de cosas más. Los narradores si bien es cierto comparten el ateísmo, éste es más bien anticlericalismo. Sus protestas son contra las "sotanas" y sus alianzas con el poder. Y por otro lado, podemos suponer que la masa obrera, por sus orígenes, campesinos en su mayoría devenidos en proletarios, son creyentes. Es dable suponer que los obreros que asisten cada 16 de julio a la fiesta de La Tirana, son los mismos que participan de las huelgas. Gran parte de la narrativa obrera, reduce a los trabajadores a una sola ocupación, en este caso la política, e ignora, por ejemplo, las actividades deportivas del proletariado.

Los textos aquí analizados se inscriben, como ya ha sido dicho, en una matriz de la modernidad ilustrada, en la que el pensamiento de izquierda, comunista y anarquista adhiere. Del mismo modo recoge esas ideas centrales y las proyecta, en este caso, sobre esa manifestación religiosa y popular que es La Tirana.

Ante esas miradas, ilustradas y modernas, la fiesta aparece como un caos, y como expresión de un pasado a superar por la fuerza de la historia. Sus personajes, obreros, revolucionarios e ilustrados, simbolizan esa fuerza.

\section{Bibliografía}

Alvarez, I., Novela y Nación en el siglo XX chileno. Ficción literaria e identidad, Colección Estudios de Literatura, Universidad Padre Alberto Hurtado, Santiago, Chile, 2009.

Bahamonde, M.,"El milagro del viejo Avelino", en Pampa Volcada, Ediciones Cultura, Santiago, 1945, pp. 61 - 85.

Bahamonde, M., Antología del cuento nortino, Universidad de Chile, Departamento de Extensión Universitaria, Antofagasta, Chile, 1966. 
Bravo-Elizondo, P., Cultura y Teatro Obreros en Chile: 1900-1930 (Norte Grande), Madrid, Libros del Meridión, 1986.

Bravo-Elizondo, P.; Guerrero Jiménez, B., Historia y Ficción Literaria sobre el Ciclo Salitrero en Chile, Iquique, El Jote Errante, Ediciones Campvs, Universidad Arturo Prat, 2000.

Chernilo, D., Nacionalismo y cosmopolitismo. Ensayos sociológicos, Ediciones Universidad Diego Portales, Santiago, Chile, 2010.

González, J. A., Breve bosquejo de la Pampa y del hombre nortino en la literatura chilena. En: Anales de literatura hispanoamericana, No 17, Editorial Universidad Complutense, Madrid, 1983, pp. 82 - 97.

Guerrero, B., Están reventando las rosas. Sociedad y literatura en el Norte Grande de Chile, Dirección de Extensión, Universidad Arturo Prat, Ediciones El Jote Errante, Iquique, 2002.

Guerrero, B., “El fenómeno de la religiosidad popular en la producción académica del Norte Grande de Chile la obra de Juan Van Kessel". En: Cuadernos Interculturales, №3, Universidad de Valparaíso, Valparaíso, Chile, 2004, pp. 45 - 56.

Guerrero, B.,"Pensamiento Ilustrado, Moral y Religión en la novela Tarapacá".En: Revista de Ciencias Sociales. No 6. Universidad Arturo Prat. Iquique, Chile, 1996, pp. 79 - 96.

Guerrero, B.,"Fútbol y nacionalismo en el norte grande de Chile". En: Fútbol, cultura y sociedad. Herrera, Rodrigo y Varas, José compiladores. Colección Seminarios 4. Universidad Academia de Humanismo Cristiano. Santiago, Chile, 2008, pp. $95-110$.

Hervieu-Léger. El peregrino y el convertido. La religión en movimiento, Ediciones del Hélenico, México, DF, 2004.

Maya, O., Mario Bahamonde, novelista. Literatura y conciencia histórica del norte chileno, Universidad Católica del Norte, Antofagasta, Chile, 1998.

Moretic, Y., El Relato en la Pampa Salitrera, Ediciones del Litoral, Santiago, 1962.

Núñez, L., La Tirana del Tamarugal del misterio al sacramento, Universidad Católica del Norte, Antofagasta, 1988.

Pérez, A., Poesía desprotegida. Compilación de poesías de periódicos antofagastinos de 1900 a 1920, Universidad Arturo Prat, Dirección de Extensión Académica y Cultural, Iquique, Chile, 1996. 
Núñez, M., La identidad pampina en Rivera Letelier. En: Acta Literaria $\mathrm{N}^{\circ} 30$, Universidad de Concepción, 2005, pp. 67 - 79.

Sabella, A., Norte Grande, Lom Ediciones, Santiago, Chile, 1997. 